\title{
Vacinação, varíola e uma cultura da imunização no Brasil
}

\author{
Vaccination, smallpox, and a culture of immunization in Brazil
}

Gilberto Hochman ${ }^{1}$

\begin{abstract}
The aim of this paper is to discuss the emergence and establishment of a "culture of immunization" in the contemporary Brazil from the eradication of smallpox. This culture is associated with a long process of introduction of vaccines, vaccination campaigns and mass vaccination undertaken by the Brazilian government since the late nineteenth century. Particular importance is attributed to the campaign to eradicate smallpox in Brazil (1966-1973). The experience of mass vaccination of the population against smallpox is contrasted with episodes of resistance as the "revolt against the vaccine", and regarded as crucial in shaping new policies and new understandings about the role of immunization in public health and its place in society Brazil.
\end{abstract}

Key words Smallpox, Vaccination, Eradication, Culture of immunization, Brazil, Global health
Resumo O objetivo deste artigo é discutir a emergência e o estabelecimento de uma "cultura da imunização" no Brasil contemporâneo a partir da erradicação da varíola. Essa cultura está associada a um longo processo de introdução de vacinas, de campanhas de vacinação e de vacinação em massa empreendidas pelo Estado brasileiro desde o final do século XIX. Particular importância é atribuída à campanha de erradicação da variola no Brasil (1966-1973). A experiência da vacinação em massa da população contra a varíola é contrastada com episódios de resistência como a "Revolta da Vacina", e considerada como crucial na configuração de novas políticas e novas compreensões sobre o papel da imunização na saúde pública e seu lugar na sociedade brasileira.

Palavras-chave Varíola, Vacinação, Erradicação, Cultura da imunização, Brasil, Saúde global
${ }^{1}$ Casa de Oswaldo Cruz, Fundação Oswaldo Cruz. Av. Brasil 4.036, sala 403. 21040-361. Rio de Janeiro RJ.hochman@coc.fiocruz.br 


\section{Introdução}

O objetivo deste artigo é discutir a emergência e o estabelecimento de uma "cultura da imunização" no Brasil contemporâneo a partir da erradicação da varíola. Essa cultura está associada a um processo de introdução de vacinas, de campanhas de vacinação e de vacinação em massa empreendidas pelo Estado brasileiro desde o final do século XIX. Particular importância é atribuída à campanha de erradicação da varíola no Brasil que vacinou e revacinou mais de 80 milhões de pessoas (1966-1973). Esta se deu no âmbito do Programa de Erradicação da Varíola da Organização Mundial da Saúde (OMS) entre 1967 e 1980, ano em que a varíola foi declarada erradicada. As vacinas e as campanhas de vacinação contra a febre amarela, da BCG e da poliomielite também foram importantes nesse processo.

Sustento que essa "cultura" se constituiu ao longo do século passado e se expressa pela adesão da população aos programas governamentais de imunização e pela demanda cada vez maior de que novas vacinas sejam oferecidas pelo poder público. O Programa Nacional de Imunizações, criado em 1975 na esteira da erradicação da varíola no Brasil, é a expressão institucional desse processo, assim como os dias nacionais de vacinação - cruciais para a erradicação da poliomielite no Brasil - são a forma mais saliente de mobilização pública em torno da imunização. Há fortes indícios e indicadores de que a população brasileira conquistou uma "cidadania biomédica" inclusiva ${ }^{1,2}$ mesmo em uma sociedade desigual, com a oferta pública de amplo pacote de imunizantes e boa cobertura da população nas campanhas de vacinação.

Grandes interesses econômicos estão envolvidos na pesquisa, produção e distribuição de vacinas, porém eles não parecem explicar individualmente a expansão da oferta governamental e a demanda e busca de imunização pela sociedade. Pelo seu caráter extraordinário, as epidemias, e o medo que elas geram, podem explicar episódios particulares de adesão a campanhas de imunização, ou a desconfiança delas, mas não explicam a imunização como rotina social. Para além do direito à imunização, uma dimensão a ser ressaltada é a aceitação ampla e ativa das vacinas e da vacinação como bens e ações positivas e públicas, independentemente dos mecanismos coercitivos existentes para fazer valer, por exemplo, a obrigatoriedade da imunização das crianças em idade escolar, mesmo durante o regime militar (1964-1985). São mecanismos que historicamente foram, e continuam sendo, pouco eficazes, e não explicam completamente a "popularização" da imunização no Brasil. Se na fase final da campanha de erradicação da varíola na Índia houve episódios coercitivos e violentos envolvendo autoridades sanitárias locais e agências internacionais ${ }^{3-5}$, o mesmo parece não ter ocorrido no Brasil. Também não assistimos no Brasil a manifestações mais explícitas de demanda por vacinas fora dos ambientes institucionais da medicina e da saúde pública como ocorreu no caso analisado por Diego Armus, no qual imprensa, doentes e famílias fizeram manifestações e petições pela introdução pelo governo de uma vacina contra a tuberculose proposta pelo médico Jesús Pueyo na Argentina do início dos anos $40^{6}$.

Esse quadro mais contemporâneo da imunização no Brasil contrasta com a resistência à vacinação que foi tão bem expressa pelo episódio da "Revolta da Vacina" de 1904 na cidade do Rio de Janeiro e por alguns episódios anteriores e subsequentes de vacinofobia no Brasil ${ }^{7-11}$. Uma constatação importante é a raridade de registros de revoltas ou resistências organizadas nas décadas posteriores. Do ponto vista comparativo, parece evidente a inexistência de fortes movimentos antivacinistas organizados no Brasil via-àvis ao mundo anglo-saxão ${ }^{12,13}$. Existem posições e ações individuais contra vacinas (ou sua obrigatoriedade) fundamentadas por argumentos de natureza religiosa, ética, política ou científica, e mesmo eventuais desconfianças em relação aos riscos de uma determinada vacina, seus custos e benefícios ou do açodamento de uma campanha. No entanto, elas não se transformaram em movimentos sociais, científicos ou profissionais contra a imunização no Brasil como aqueles encontrados nos Estados Unidos ou na Inglaterra do século XXI.

Este artigo especula sobre os processos históricos que conformaram essa "cultura da imunização" no Brasil. Afinal, sessenta anos depois de uma revolta contra a vacinação obrigatória, a população, em vez de fazer barricadas, não só saiu de suas casas como formou filas e aglomerou-se em praças públicas para ser vacinada entre 1967 e 1973, no período mais duro de um regime autoritário avesso a concentrações populares. Manifestou uma espécie de "civismo imunológico", parafraseando Warwick Anderson $^{2}$. Depois da erradicação da varíola (certificada em 1973), a sociedade continuou, além da vacinação de rotina, a participar de campanhas públicas, em particular aquelas contra a poliomielite, e mais recentemente as de sarampo, ru- 
béola, influenza, entre outras doenças imunopreviníveis, participação atestada pelos resultados de cobertura da vacinação e do controle e mesmo a possível erradicação dessas doenças no Brasil. O sucesso da imunização certamente reforçou sua credibilidade social.

A demanda e a oferta por mais vacinas pode ser associada à compreensão consagrada na Constituição Federal de 1988 de que a saúde (e a imunização) é um direito a ser garantido pelo Estado. No caso brasileiro, a cesta de vacinas disponíveis gratuitamente pelos serviços públicos de saúde é maior do que aquela recomendada pelas organizações de saúde internacionais como a Organização Pan-Americana da Saúde e a Organização Mundial da Saúde (Opas/OMS) e maior do que o ofertado pelos demais países da América Latina e por muitos países da Organização para Cooperação Econômica e Desenvolvimento (OECD).

A imunização como direito foi consagrada pela redemocratização do país a partir de 1985, mas não é um resultado desse contexto específico. A imunização como cultura também transborda os limites explicativos de contextos históricos singulares ou causalidades únicas. É produto de uma longa trajetória histórica das políticas de saúde associadas ao processo de construção de Estado no Brasil ${ }^{14}$. A vacina e a vacinação foram tecnologias de incorporação de territórios e populações ao Estado nacional, de promoção da cidadania biomédica e da regulação da interdependência sanitária, isto é, dos efeitos negativos da doença de uns sobre terceiros ${ }^{15}$. Também não são produtos desencarnados de interesses. Dizem respeito a poder, desigualdade, inclusão, controle, direitos civis, políticos e sociais. Porém, a construção de Estado é um processo histórico em que os resultados, em transformação, não são intencionais, nem previsíveis ou antecipáveis por indivíduos, grupos e instituições que dele participaram ao longo do tempo ${ }^{16}$.

Na sequência do texto, apresentarei uma breve e seletiva história da vacinação antivariólica e da erradicação da varíola no Brasil, que oferece algumas indicações para a conformação de uma "cultura da imunização" e para o virtuosismo da política de imunização no país. Ao final, retomarei os argumentos apresentados discutindo características, desafios e dilemas dessa "cultura" e dessa política à luz da história das campanhas de vacinação.

\section{A varíola e sua erradicação no Brasil}

A história da erradicação da varíola no Brasil não está simplesmente contida nos marcos institucionais definidos pela criação da Campanha de Erradicação da Varíola (CEV) em agosto de 1966 e a certificação internacional de erradicação obtida em agosto de 1973. A história da vacinação antivariólica no Brasil data do início do século XIX ${ }^{17}$, e a doença esteve no topo da agenda sanitária do país até o final da década de 1910. Nos anos 1920 e 1930, a febre amarela ocupou o lugar de destaque. A partir de fins da década de 1940, a prioridade foi o controle, e depois, a erradicação da malária em consonância com a agenda da saúde internacional nos anos de 1950. O predomínio de sua forma benigna (minor) a partir dos anos 30 produziu uma "convivência social" com a varíola e dificuldades no diagnóstico específico ${ }^{18}$.

Foi no início do século XX que a vacinação antivariólica, a sua obrigatoriedade e a resistência de setores da sociedade se entrelaçaram em um episódio dramático. A República instaurada em novembro de 1889 tinha como metas a modernização do país e o seu ingresso no mundo civilizado. O comércio internacional, a imigração, o fluxo marítimo e a vida econômica e social eram frequentemente paralisados pelas epidemias de febre amarela e varíola. A primeira tentativa efetiva para mudar o status quo sanitário e péssima imagem internacional da capital federal e do Brasil foi uma ampla reforma urbana inspirada nas reformas de Haussmann em Paris. Essas reformas foram acompanhadas por grandes campanhas sanitárias contra a febre amarela, a varíola e a peste bubônica durante a presidência de Rodrigues Alves (1903-1906) ${ }^{19}$. Estas foram lideradas pelo médico Oswaldo Cruz, diretor da saúde pública entre 1903 e 1909, e que desde 1902 dirigia o Instituto Soroterápico Federal, criado em 1900 (renomeado Instituto Oswaldo Cruz em 1907) para produzir soros e vacinas ${ }^{17}$. Na gestão de Cruz, o Instituto se transformaria em um importante centro de produção de soros e vacinas e de pesquisa nos campos da medicina tropical e da microbiologia ${ }^{20-22}$.

Em 1904, a capital federal registrara quase sete mil casos de varíola. Dado que o combate à varíola dependia da vacina, Oswaldo Cruz apresentou ao Congresso Nacional um projeto de lei reinstaurando a obrigatoriedade da vacinação e a revacinação em todo o país - até então nunca cumpridas. A nova lei continha cláusulas rigorosas que incluíam multas aos refratários e a exigência de atestado de vacinação para matrículas 
nas escolas, acesso a empregos públicos, casamentos e viagens, além de possibilitar os serviços sanitários adentrar residências para vacinar seus moradores ${ }^{8,23}$.

A aprovação da lei da vacinação obrigatória em outubro de 1904 foi precedida de acalorados debates. A publicação pelos jornais do que seria o decreto de regulamentação da lei - denominado pela população de "Código de Torturas" - foi o estopim para a eclosão de uma revolta que reuniu grupos com motivações e objetivos muito diferentes. A oposição à vacinação obrigatória congregou de modo não articulado antivacinistas, militares e civis monarquistas que vislumbraram a possibilidade de reinstaurar o Império, positivistas que reagiam a qualquer obrigatoriedade e intervencionismo estatais nas práticas de curar, sindicatos que lutavam por melhores salários e contra a carestia, militares e elites políticas que faziam oposição ao presidente, setores da população urbana que entendiam a vacinação como uma invasão da privacidade do lar e um ataque à moralidade da família e setores populares que foram duramente afetados pelas reformas urbanas com a destruição das habitações consideradas insalubres e a expulsão dos pobres do centro da capital saneada e embelezada ${ }^{8-11,23-25}$. Alguns autores sugerem que parte da resistência à vacinação derivava de ela ser compreendida como uma intervenção sobre práticas de variolização associadas a divindades cultuadas por grupos afrodescendentes, que correspondiam a um percentual expressivo da população pobre da cidade do Rio de Janeiro ${ }^{7}$. O episódio consagrado como a "Revolta da Vacina" paralisou a cidade do Rio de Janeiro entre os dias 10 e 16 de novembro de 1904, quando foi decretado o Estado de Sítio, iniciado o controle da rebelião e a dura repressão aos revoltosos com prisões e deportações ${ }^{8}$.

Passado esse período mais turbulento, a vacinação continuou sendo realizada e foi sendo incorporada lentamente ao cotidiano da população da capital e das principais cidades do país. Houve um rápido declínio da mortalidade por varíola, que caiu praticamente a zero no ano de 1906. As campanhas de vacinação iniciadas por Oswaldo Cruz em 1904 tiveram papel importante no declínio dos casos de varíola nas duas décadas subsequentes, ainda que este tenha sido interrompido por surtos importantes. Uma nova epidemia paralisou a capital em 1908 com inédita mortalidade de 1.000/100.000 habitantes e um registro de 9.900 casos, superando as de 1887 e $1891^{26,27}$. Entretanto, apenas quatro anos depois de a "Revolta da Vacina" paralisar o Rio de Janei- ro, não há registros de resistência popular organizada à vacinação empreendida pelos serviços sanitários, assim como nos surtos de 1914 e de 1926, o último que atingiu o Rio de Janeiro, com 4.140 casos de varíola registrados ${ }^{26}$.

O saneamento da capital federal produziu efeitos na opinião pública sobre a importância da vacina antivariólica e do papel do governo em fazer cumprir a obrigatoriedade. Recursos aos tribunais contra a vacinação tornaram-se menos frequentes, à medida que o Supremo Tribunal Federal firmava jurisprudência sobre as restrições às liberdades individuais em benefício da saúde pública, desde que prescritas em lei e não em regulamento ${ }^{28}$. Em 1926, os jornais da capital criticavam duramente o fato de um juiz federal do Estado do Maranhão ainda conceder habeas corpus contra a obrigatoriedade da vacina antivariólica a um grupo de indivíduos que alegava estar sendo constrangido pelo diretor estadual de saúde. Essa decisão acabou sendo cassada pelo Supremo Tribunal ${ }^{29}$.

No ano de 1930, o número de casos havia chegado a zero na capital e manteve-se muito baixo durante toda a década, ainda que continuassem ocorrendo eventuais surtos em várias cidades do país ${ }^{26,27}$. Ao final da Primeira República (1889-1930), a varíola, que junto com a febre amarela e a peste bubônica tinha sido o foco das ações da saúde pública brasileira nas primeiras décadas do século XX, deixou de ser uma prioridade do governo brasileiro e desapareceu da agenda da saúde pública. Durante o Primeiro Governo de Getúlio Vargas (1930-45), mesmo se tratando de um período de forte centralização política e administrativa, aprofundada em seu período ditatorial a partir de 1937, o entendimento era de que a produção da vacina e a vacinação deveriam ficar sob responsabilidade dos governos estaduais e municipais. Na criação do Ministério da Educação e Saúde em 1930, e no estabelecimento em 1941 de serviços nacionais dedicados a combater as doenças consideradas mais importantes para o país, o combate à varíola não foi contemplado $^{30}$. As prioridades eram a tuberculose, a lepra, a malária e as chamadas endemias rurais ${ }^{31}$.

O sucesso de seu controle nas campanhas das duas primeiras décadas do século XX e a prevalência a partir de 1930 da sua forma benigna produziu resultados reversos. Ao contrário da febre amarela, da lepra, da malária e da tuberculose, a varíola não logrou criar uma tradição de pesquisa e de desenvolvimento de técnicas e tecnologias, não penetrou como tema relevante nas escolas médicas, não organizou uma comunidade de 
especialistas e não produziu rotinas de notificação, registro e vigilância. Até a década de 1950, as respostas do Estado Republicano ainda eram semelhantes às do Império, isto é, ações emergenciais para enfrentar surtos epidêmicos que não organizavam estruturas mais perenes, sejam em nível federal ou estadual ${ }^{18}$.

O governo federal cooperava tecnicamente e apoiava o suprimento de imunizantes, mas em geral de forma insuficiente e descontínua. Qualquer esforço para ampliar coberturas vacinais passava a depender da iniciativa dos governos estaduais e locais, que tinham outras prioridades ou mesmo incapacidade técnica e financeira para produzir ou comprar vacinas e vacinar rotineiramente ${ }^{32}$. As exceções eram as vacinas BCG e de febre amarela, que era da competência do governo federal ${ }^{33,34}$. Ainda que casos e surtos epidêmicos ocorressem e os doentes com as manifestações graves fossem muito visíveis, a invisibilidade política da varíola fez com que ela sequer estivesse na pauta da I Conferência Nacional de Saúde realizada no Rio de Janeiro em novembro de 1941, durante a qual se discutiram os principais problemas de saúde do país e possíveis soluções ${ }^{35}$.

Esse desaparecimento começou a ser revertido com o movimento da Organização Pan-Americana da Saúde (Opas) e a Organização Mundial da Saúde (OMS), que estavam discutindo a erradicação da varíola em escala global, aprovada formalmente pela Assembleia Mundial da Saúde em $1959^{36}$. Nesse momento, o Brasil era o único país da América do Sul que não tinha um programa de vacinação sistemático e de âmbito nacional, ainda que registrasse a grande maioria dos casos da região.

Mudanças no cenário da saúde internacional e nacional na metade do mandato de Juscelino Kubitschek (janeiro de 1956-janeiro de 1961) tiveram impacto na reintrodução da varíola na agenda de saúde brasileira. A proposta de erradicação da varíola esteve presente nas resoluções da Opas e da OMS desde 1949. Em 1959, a resolução da XI Assembleia Mundial da Saúde sobre "a necessidade e urgência de uma campanha global de erradicação" teve consequências importantes ${ }^{37}$.

Em sua mensagem ao Congresso Nacional na abertura dos trabalhos legislativos do ano de 1958, Kubitscheck indicava que a varíola também se tornara passível de erradicação ${ }^{38}$. Ainda que o foco principal continuasse sendo a malária, esse era o primeiro discurso presidencial desde 1950 que mencionava explicitamente a varíola como um dos principais problemas sanitários do país e a sua futura erradicação como meta governamen- tal desde a redemocratização. Ações anunciadas por JK buscavam agir contra o recrudescimento dos casos de varíola no Brasil, país com o maior número de casos na região, seguido da Colômbia e do Equador ${ }^{26,39}$. Em primeiro lugar, o tamanho do país e sua população rarefeita dificultavam o processo de imunização, uma vez que os processos utilizados para fabricação e conservação da vacina não conservavam efeito imunizante por períodos mais longos. Nesse sentido, o governo, com o apoio da Opas/OMS, capacitaria os laboratórios nacionais para produzir a vacina liofilizada. Em segundo lugar, as dificuldades dos governos estaduais e municipais em empreender campanhas rotineiras de vacinação produziam baixa cobertura vacinal e não detinham surtos esporádicos em cidades. Disso resultava um elevado número de casos em comparação com demais países da região da Américas e um desconfortável papel de exportador de casos para outros países, como por exemplo o último caso no Canadá ${ }^{40}$. Na ausência de órgãos específicos, a estratégia do governo foi buscar mobilizar as instituições federais de saúde para realizar programas de vacinação em massa em apoio aos estados e municípios.

Há um duplo movimento nacional e internacional que pode explicar essa mudança. O governo JK estava diante de dificuldades para financiamento de qualquer programa de saúde diante da prioridade nos investimentos em infraestrutura para o desenvolvimento econômico e cumprir a meta de transferir a capital e inaugurar Brasília até o final de sua administração. $\mathrm{O}$ ano de 1958 também foi significativo para as mudanças nas relações interamericanas. Apesar de o Brasil se inserir plenamente como zona de influência dos EUA, desde o fim da Segunda Guerra Mundial esse relacionamento vinha sendo marcado por crescentes divergências, principalmente no terreno econômico. De um lado, junto com os países latino-americanos, assolados por problemas econômicos crônicos que apenas se agravaram com o final da guerra, continuava alimentando esperanças de que os EUA assumissem algum tipo de compromisso que implicasse recursos destinados a amenizar suas mazelas e acelerar seu desenvolvimento econômico ${ }^{41,42}$.

Aproveitando-se da conjuntura favorável de manifestações antiamericanas na América Latina, Kubitscheck enviou uma carta ao presidente Eisenhower, em 28 de maio de 1958, em que lamentava o grau de deterioração das relações regionais e propunha uma revisão do pan-americanismo. Denominada de Operação Pan-Ameri- 
cana (OPA), a iniciativa diplomática era baseada na proposta de que os EUA assumissem um compromisso político com a erradicação do subdesenvolvimento latino-americano que incluísse a alocação de investimentos públicos, contribuindo assim para a estabilidade política e barreira ao comunismo ${ }^{41}$.

As mudanças de posicionamento do governo norte-americano em relação às relações com a América Latina, principalmente depois da Revolução Cubana, resultaram no lançamento da Aliança para o Progresso pela administração John F. Kennedy, expressa na Carta de Punta del Este, documento assinado pelos países membros da Organização dos Estados Americanos (OEA), na conferência realizada no Uruguai em agosto de $1961^{43,44}$. No "Plano Decenal de Saúde Publica da Aliança para o Progresso", anexo à Carta, havia a menção explícita à erradicação da varíola, incorporada na agenda de reformas sociais a serem promovidas sob os auspícios dos EUA ${ }^{45}$.

Sob pressão e percebendo oportunidades de obter recursos para melhoria nas condições de saúde da população, o Brasil foi se integrando na agenda da saúde internacional e na nova política interamericana. No caso específico da malária, a pressão era maior com a decisão norteamericana de que o financiamento só poderia ser carreado para programas nacionais de erradicação, já como resultado da "guerra contra a malária" declarada em 1958 pela administração Eisenhower ${ }^{46}$. Entre 1958 e 1961, o Departamento Nacional de Endemias Rurais (DNERu), órgão do Ministério da Saúde, iniciou um programa de vacinação antivariólica que atingiu 2.600.000 pessoas em 18 unidades federativas ${ }^{47,48}$. Ainda que limitada, e fora do escopo das ações do DNERu, essa foi uma primeira ação de alcance nacional, utilizando uma estrutura já existente, com forte presença no interior do Brasil e em áreas mais pobres, para aumentar a cobertura vacinal. Ainda em 1961 foi iniciada a fabricação da vacina liofilizada no Instituto Oswaldo Cruz; que depois também seria fabricada em institutos vacínicos do Sul e do Nordeste do país ${ }^{33}$.

Cabe ressaltar que as presidências de Jânio Quadros (1961) e de João Goulart (1961-64) foram marcadas por grande instabilidade econômica e política que culminou no golpe civil-militar de 31 de março de 1964. Este sepultou o período democrático iniciado em 1945 e instaurou um regime autoritário que perdurou até 1985 . O efêmero governo Quadros e o instável governo Goulart buscaram uma aproximação com o chamado movimento dos países não alinhados e uma política externa mais independente (dos EUA $)^{49}$. No campo da saúde, o início dos anos 60 foi marcado no Brasil pela emergência dos críticos dos modelos verticais e centralizados e a chamada "concepção restrita" das relações entre saúde e desenvolvimento. Eram os chamados "sanitaristas desenvolvimentistas", que conquistavam espaço no Estado e nas principais associações profissionais. Estes estiveram associados a projetos nacionalistas de reforma social, em particular a reforma agrária, que estavam em discussão e polarizavam o país. Também propugnavam maior descentralização e integração das ações de saúde. Desse modo, o programa de erradicação da malária era duramente criticado, e a criação de uma nova campanha de erradicação, também centralizada e vertical, não era vista com simpatia, assim como a participação dos Estados Unidos da América em assuntos domésticos como saúde pública ${ }^{50-52}$.

Durante todo o mês de janeiro de 1962, os jornais anunciavam em suas páginas que havia uma ameaça de possível epidemia de varíola no Brasil vinda da Europa, em particular da Inglaterra, que experimentava um surto naquele momento, inclusive importando vacinas da Argentina. O alarme era ampliado pelo fato de que $60 \%$ da população infantil do Rio de Janeiro não estava imunizada contra a doença. A imprensa revelava (e conformava) uma concepção presente na opinião pública de que a "ameaça" era externa, apesar de a varíola ser reconhecidamente endêmica no país. No entanto, denunciava o fato de que a cidade mais importante não lograva proteger a maioria de suas crianças da varíola, apesar da obrigatoriedade do atestado de vacinação inclusive para matrícula nas escolas ${ }^{53-54}$.

No final de janeiro de 1962, o governo João Goulart decidiu criar a Campanha Nacional Contra a Varíola. Esta foi a primeira organização nacional criada para coordenar o combate à doença em quase sessenta anos. Ela envolvia em sua coordenação vários órgãos de saúde do Ministério da Saúde e o representante da Opas/OMS no Brasil $^{55}$. Entre outubro de 1962 e julho de 1966, foram vacinadas 23.500 pessoas, com percentuais de cobertura bastante desiguais, que variaram de 8,7\% nos estados da região Sul do país a 41,9\% na região Nordeste. Ainda que significasse um patamar superior de envolvimento do governo federal, esta campanha dependia fundamentalmente dos estados, com situações epidemiológicas e condições financeiras muito diferentes. Também contou com poucos recursos humanos e financeiros federais, envolvidos mais no trabalho de norma- 
tização, planejamento e no trabalho epidemiológico $^{32,56,57}$. Baseada nos princípios de coordenação nacional e descentralização executiva, que depois seriam utilizados na erradicação, o governo federal não investiu e mobilizou-se para viabilizar a eliminação da doença. Sob o impacto desse primeiro esforço nacional, houve redução do número de casos reportados, de 9.600 com 160 óbitos, em 1962, para 3.623 casos e vinte óbitos no ano de 1966, números que talvez fossem explicados pela precariedade do sistema de notificação e registro até então existente. De qualquer forma, no mesmo período a incidência da doença decrescera mais rapidamente em outros países da região, que a erradicaram em meados da década de 1960. No ano de 1966, o Brasil era a última fronteira da varíola nas Américas, alvo crescente de pressões internacionais ${ }^{39}$.

Os desafios das autoridades brasileiras para organizar um programa de erradicação da varíola eram imensos. Não havia consenso entre médicos e autoridades da saúde pública sobre a importância da varíola ante outras doenças imunopreveníveis, tais como a poliomielite, e sobre os riscos da vacinação em massa. A prioridade nacional era a malária, cuja campanha de erradicação estava sendo intensificada e consumia parte dos recursos nacionais e monopolizava os recursos internacionais, em particular da USAID, ao mesmo tempo que os modelos verticais e centralizados vinham sendo criticados no Brasil e no exterior. A produção de vacinas era insuficiente, com tecnologias consideradas antiquadas e com pouco controle de qualidade. Muitas eram as ausências: ausência de laboratórios de referência para diagnóstico; de estruturas nacionais e experiências anteriores para a vacinação em massa; de quadros técnicos especializados em número adequado; de informações detalhadas em âmbito nacional; de um sistema de vigilância epidemiológica; de legislação capaz de garantir a obrigatoriedade da vacinação e revacinação e mesmo de demandas de uma população cada vez mais jovem e urbana, que tinha menos familiaridade com a varíola do que gerações anteriores, em particular na sua forma mais grave e com as mortes por ela causadas. A varíola em sua forma minor era subnotificada. Para além da crise econômica e política que resultou no fim do regime democrático instituído em 1945, as ações contra a varíola eram, portanto, imersas em muitas dúvidas e tinham muitos obstáculos científicos, técnicos, administrativos e tecnológicos ${ }^{18}$.

Dadas as crescentes pressões de governos estrangeiros e agências internacionais, os compro- missos assumidos e reafirmados nas Conferências Pan-Americanas e Assembleias Mundiais da Saúde e as novas condições políticas e ideológicas derivadas do golpe militar de 31 de março de 1964, o governo do Marechal Castelo Branco (1964-1967) inseriu o Brasil no esforço global das "erradicações". Em 1965 o país adotou um programa exclusivo de erradicação da malária, abandonando definitivamente ações de controle que vinham sendo mantidas desde $1958^{46}$. Em agosto de 1966, foi criada a Campanha de Erradicação da Varíola (CEV) com a finalidade exclusiva de eliminar a doença do país, e em 1967 a CEV passou a se subordinar diretamente ao ministro da Saúde.

A justificativa do então ministro da Saúde Raimundo de Brito é elucidativa dos motivos que levavam o governo a erradicar a varíola. A doença merecia atenção especial do governo não apenas pelo seu aspecto nosológico, mas fundamentalmente também pela sua importância política, uma vez que o Brasil "lamentavelmente ainda se inscreve entre os mais importantes focos de varíola do mundo e o mais relevante do continente americano" ${ }^{58-63}$. Os contextos nacional e internacional se entrecruzavam. A CEV é instituída com um orçamento no qual $1 / 3$ dos recursos vinham da Aliança para o Progresso, além do apoio efetivo do Center for Diseases Control (CDC), do governo canadense, da Opas e da $\mathrm{OMS}^{64}$. A USAID concederia recursos mais expressivos para a vacinação em massa no final da campanha, em 1970 e $1971^{65}$. Do lado brasileiro, a vacinação antivariólica, o declínio do número de casos e a meta inicial de erradicação da doença já no ano de 1968 serviram como propaganda do governo militar. No lançamento da CEV, o governo militar divulgava que em dois anos já tinha dobrado o número de vacinações realizadas pelo governo deposto em $1964^{66,67}$.

Dado um contexto nacional e internacional favorável, o "déficit brasileiro" no combate à varíola foi transformado, num curto período de tempo, em vantagem e oportunidade para o governo militar e para um grupo de profissionais de saúde, em particular para jovens médicos, virologistas e epidemiologistas não necessariamente alinhados politicamente com o regime. A erradicação da varíola poderia ser uma resposta política do Brasil à comunidade internacional que permitiria que o governo obtivesse mais reconhecimento e legitimidade em um momento em que aumentava a censura à imprensa e a repressão aos movimentos de contestação. Em 1968, o Brasil era o único país das Américas com casos 
autóctones. Por sua vez, a campanha possibilitava a ampliação da agenda de saúde para além da erradicação de uma doença, criava oportunidades para o campo de produção de vacinas e abria espaços profissionais e políticos para os que nela se envolveram.

A estruturação da CEV aprofundou uma tendência anterior, agora de forma bastante coordenada e planejada e com recursos financeiros nunca antes invertidos na varíola: em vez de montar uma grande estrutura que poderia se burocratizar, semelhante à da erradicação da malária, optou-se pela utilização de pessoal de outros órgãos do Ministério da Saúde, da própria Campanha de Erradicação da Malária, dos serviços estaduais e municipais de saúde e da Fundação Serviços Especiais de Saúde (FSESP), origem de parte do grupo que dirigiu a CEV. Ao utilizar recursos e estruturas já existentes e treinadas, e com a flexibilidade para contratar, treinar e dispensar pessoal a partir de coordenações estaduais, a erradicação da varíola não seguiu o modelo vertical e centralizado que aparentemente representaria e reforçaria ${ }^{56}$. Mesmo em um governo autoritário e centralizador, as ações para erradicação da varíola inovaram e realizaram o que a campanha de 1962 não conseguira: utilizar o máximo dos recursos e infraestrutura existentes nos estados e municípios sob coordenação e planejamento federal.

De 1966 a 1971, o programa de erradicação, ao mobilizar recursos disponíveis de órgãos federais, estaduais e municipais, operou com um número exíguo de 3.563 funcionários, sendo 654 vacinadores e 613 condutores de veículos. Outra inovação importante foram as técnicas de vacinação utilizadas. A partir de experimentos realizados em 1965 junto com o CDC em duas capitais de estados do Norte do Brasil, decidiu-se pelo uso de jet-injector (no caso, Ped-o-Jet) ${ }^{68,69}$ nas zonas urbanas, permitindo maior número de vacinações por dia por uma equipe de vacinadores e menos desconfiança da população e nas zonas rurais, e nas situações de vacinação casa a casa, seria empregada a agulha bifurcada. Entre 1967 e 1971, a CEV contou com 332 injetores, doação da Opas/OMS. A mobilidade das equipes de vacinação deveria ser garantida por 230 veículos, em grande parte obtidos com recursos internacionais. Esses foram os recursos utilizados para produzir um total de 81.745 .290 vacinações, que correspondia a $84 \%$ da população brasileira $^{70}$.

A estratégia para vacinação em massa nas áreas urbanas, ou com significativa concentra- ção de pessoas, foi a de mobilização da população para grandes encontros em lugares públicos, que marcavam a chegada dos vacinadores e o início da vacinação. Os líderes políticos locais foram envolvidos no processo de mobilização e convocação da população e se tornavam aliados dos coordenadores estaduais da CEV. Festas populares, romarias, encontros religiosos, feiras, manifestações artísticas populares, quartéis, escolas públicas, paradas de ônibus e grandes empresas foram locais utilizados para vacinação em massa. As equipes deveriam estar preparadas para estender a vacinação até a noite para dar conta de todos os que compareciam. Fazia parte dessa estratégia explícita e deliberada de vacinação em lugares públicos tanto o treinamento de novos vacinadores como seu efeito demonstração para a população e autoridades. Tudo isso potencializado pela presença da imprensa ${ }^{56,71}$.

Fosse qualquer o método e estratégia de vacinação, considerava-se imprescindível obter suficiente motivação da comunidade, trabalhando seus lideres naturais e utilizando meios de divulgação e demonstração adequados ao nível educacional das referidas comunidades ${ }^{56}$. A convocação era feita pelos jornais, alto-falantes, cartazes e filmes nas escolas. O efeito demonstração se fazia também com a vacinação em público de autoridades, líderes políticos, artistas e esportistas, o que tinha repercussão na imprensa e na população convocada a se vacinar voluntariamente. Essa inovação foi reproduzida depois nos "Dias Nacionais de Vacinação" utilizados para a campanha antipoliomielite no Brasil. O ambiente da campanha era assim descrito por um jornalista no final da fase de vacinação em massa: Trezentos funcionários do Ministério da Saúde, espalhados em 150 postos, iniciaram ontem no Recife (capital do Estado de Pernambuco, região Nordeste), a Campanha de Erradicação da Varíola, vacinando 78.450 pessoas. $O$ sucesso no primeiro dia entusiasma os vacinadores, que têm certeza de que vão acabar o trabalho num prazo muito menor do que o estabelecido. Quando terminar a vacinação em Pernambuco, o grupo seguirá para Alagoas, Rio Grande do Norte e depois Piauí, os últimos estados brasileiros a serem beneficiados pela Campanha ${ }^{72}$.

Uma rigorosa legislação foi baixada para garantir a vacinação e a revacinação com a obrigatoriedade do certificado para a retirada de qualquer documento público, para receber salários, para matrícula nas escolas e viagens ao exterior, por exemplo. Sessenta anos depois da Revolta da Vacina, não existem registros de resistências à vacinação. Mas a obrigatoriedade legal não pa- 
rece ter sido o aspecto decisivo, mesmo considerando que o país estava sob um regime autoritário. Essas sanções atingiam apenas uma pequena parcela da população. Parte expressiva da população não tinha documentos oficiais e prescindia deles, a maioria da população não viajava para o exterior, o acesso ao ensino público não era universal e o trabalho informal era regra em grandes áreas do país. Ao contrário do modelo da campanha de erradicação da malária, que prescindiu de qualquer mobilização ou negociação social, a vacinação antivariólica em massa tinha que mobilizar ativamente a população e se tornou motivo para encontros populares em praças e espaços públicos por todo o país. Esse processo aumentou o contato da população com os serviços de saúde e a compreensão da vacina como bem público oferecido pelo Estado.

Um dos obstáculos ao sucesso da vacinação em massa seria a tecnologia utilizada de produção da vacina, as dificuldades de conservação dos estoques e a quantidade de vacinas necessárias. Acordos com a Opas/OMS permitiram transferência de tecnologia e equipamentos para modernização e aumento da produção da vacina, e a vacina produzida por três laboratórios nacionais passou a ser testada periodicamente no $\mathrm{Ca}$ nadá $^{73,74}$. Entre 1966 e 1971, o Brasil produziu 268.226.000 doses de vacina liofilizada ${ }^{39}$. A partir da modernização e da produção em larga escala da vacina antivariólica, se estruturaram as bases do que seria o Programa Nacional de Imunizações (PNI), criado em 1975 $5^{75,76}$.

Outro obstáculo era a inexistência da vigilância epidemiológica que, no plano inicial da CEV, seria um sistema a ser implantado concomitantemente com as atividades de vacinação em massa e deveria operar nas áreas onde a fase de vacinação massiva tivesse sido completada ${ }^{77}$. Porém, dificuldades financeiras e operacionais só permitiram que o sistema de vigilância começasse a ser instalado em 1969, ano em que se registrou um aumento e o maior número de casos desde o início da campanha, em 1966. Esse obstáculo começou a ser superado com a criação de Unidades de Vigilância Epidemiológicas (UVEs) e de Postos de Notificação sob responsabilidade de cada estado para as fases de consolidação da campanha, reforçando as articulações entre diferentes esferas de governo. Em 1970, todos os estados da federação tinham suas UVEs, e havia Postos de Notificação cobrindo 90\% dos municípios brasileiros, constituindo-se em embrião do Sistema Nacional de Vigilância Epidemiológica, criado em $1975^{78}$.
Participantes e observadores têm divergido sobre as bases do sucesso do programa brasileiro. Para uns teria sido resultado da vacinação de massa, para outros da vigilância epidemiológica, visão esta que se tornou hegemônica nos relatos oficiais e comemorativos ${ }^{79}$.

A análise histórica da experiência brasileira aponta outra direção. Em 1971, foram reportados os últimos 19 casos de varíola no Brasil na cidade do Rio de Janeiro. Em agosto de 1973, o governo do general Garrastazu Médici (19701974) recebeu de uma comissão internacional a certificação da erradicação da varíola no Brasil e, por conseguinte, da região das Américas ${ }^{79}$. A vacinação antivariólica continuou obrigatória na rotina dos serviços de saúde até o ano de 1975. Em maio de 1980, a Assembleia Mundial da Saúde declarava que a "varíola estava morta".

\section{Discussão}

A história da varíola e da vacinação pode ser lida como um ciclo denominado de "prioridade, invisibilidade e erradicação"18. A história da imunização e da varíola no Brasil a partir do início do século XIX está marcada pelas oscilações na percepção do poder público de sua importância epidemiológica e política vis-à-vis a outras doenças de caráter epidêmico e endêmico. De sua proeminência na agenda do governo imperial e nos primórdios da república, a varíola desapareceu gradualmente das preocupações dos governos brasileiros a partir de 1920, independentemente de seu caráter autoritário ou democrático, ou de características mais centralizadoras ou descentralizadoras. O retorno da varíola à agenda sanitária nacional a partir de 1958 esteve associada a diferentes articulações do Brasil com a saúde internacional e com o contexto internacional marcado pela Guerra Fria, que teve desdobramentos específicos na América Latina.

Porém, apesar de um contexto marcado pelos benefícios do alinhamento aos EUA e à agenda de erradicação da OMS e pela própria necessidade de o governo militar produzir fatos e resultados legitimadores, o sucesso em se erradicar a varíola em sete anos foi também resultante de adaptações, inovações e ampliação locais e nacionais da agenda da saúde internacional. A erradicação da varíola foi a oportunidade para a constituição de um Programa Nacional de Imunizações e um Sistema Nacional de Vigilância Epidemiológica, com seus subsistemas estaduais, resultados certamente não antecipados pelas agências internacionais e 
de cooperação bilateral, nem sequer imaginados pelos primeiros dirigentes do regime militar ou pelos profissionais envolvidos na campanha.

A experiência de vacinação antivariólica em massa da população brasileira é algo incomparável na história da saúde no Brasil, e mesmo da saúde internacional. É fato que a vacinação contra a febre amarela, contra a tuberculose e a poliomielite nos anos 40 e 50 foram aumentando a convivência da sociedade com vacinas e seus possíveis benéficos efeitos. Porém, as dezenas de milhões de doses de vacinas aplicadas em cinco anos, com uso aparentemente residual de meios coercitivos, modificaram a trajetória da imunização no Brasil. Esta "cidadania biomédica" foi forjada no tempo e, até a década de 1980, descolada dos direitos políticos que a conformariam como democrática e dos circuitos de mercado.

A erradicação da poliomielite e a meta de erradicação de outras doenças imunopreveníveis são consequências mais diretas das estruturas que emergiram da erradicação da varíola, assim como esta foi um episódio que influenciou a tendência de uma crescente oferta gratuita de vacinas para uma sociedade que parece cada vez mais deman- dar imunização e acolhe iniciativas de se expandir a cesta de vacinas ofertadas pelos serviços de saúde. Mas nem sempre o "civismo imunológico" dessa cidadania é saliente. Ele pode sofrer abalos como os que ocorreram na epidemia de gripe suína (2009), quando desconfianças sobre a vacina e sobre campanha de vacinação tiveram impacto sobre a cobertura da população-alvo.

Vacinas, vacinadores e campanhas de vacinação fizeram parte do longo processo de estabelecimento da autoridade sanitária no Brasil. Territórios e populações foram incorporados ao Estado nacional a partir de artefatos como agulhas, lancetas, seringas, injetores e imunizantes. As marcas indeléveis da vacina, ao substituírem as também indeléveis marcas da varíola, conformaram quase que fisicamente, e ao mesmo tempo, o poder público e a imunidade da população. A agenda global de imunização, a complexidade do cenário atual da saúde internacional, a capacidade e os limites do Estado brasileiro em responder às demandas por mais e melhores vacinas e o lugar da imunização no Sistema Único de Saúde indicarão as possibilidades e os caminhos dessa "cultura da imunização".

\section{Agradecimentos}

Este artigo é um dos resultados de pesquisa financiada por bolsa de produtividade do $\mathrm{CNPq}$ e pelo Programa Papes/Fiocruz/CNPq. É uma versão revista da apresentação feita no simpósio Smallpox Eradication after 30 years: lessons, legacies and innovations (SEC2010), realizado na Fiocruz, Rio de Janeiro, em agosto de 2010. Esse simpósio contou com o apoio de inúmeras organizações e agências de fomento. No caso das sessões dedicadas à história da varíola, agradeço em particular à Secretaria Nacional de Vigilância em Saúde/Ministério da Saúde, à Faperj, ao $\mathrm{CNPq}$ e ao Wellcome Trust. Agradeço ao Instituto de Tecnologia em Imunobiológicos (Biomanguinhos) pelo apoio a este número temático. Este artigo é dedicado à memória de Clara Cohen Hochman, educadora sanitária. 


\section{Referências}

1. Epstein S. Inclusion: the politics of difference in medical research. Chicago: University of Chicago Press; 2007.

2. Anderson W. Colonial pathologies: American tropical medicine, race, and hygiene in the Philippines. Durham, N.C.: London: Duke University Press; 2006.

3. Greenough P. Global immunization and culture: compliance and resistance in large-scale public health campaigns. Soc Sci Med 1995; 41(5):605-607.

4. Greenough P. Intimidation, coercion and resistance in the final stages of the South Asian Smallpox Eradication Campaign, 1973-1975. Soc Sci Med 1995; 41(5):633-645.

5. Bhattacharya S. Expunging variola: the control and eradication of smallpox in India, 1947-1977. New Delhi: Orient Longman; 2006.

6. Armus D. "Queremos a vacina Pueyo!!!": incertezas biomédicas, enfermos que protestam e a imprensa Argentina, 1920-1940. In: Hochman G, Armus D, organizadores. Cuidar, controlar, curar: ensaios históricos sobre saúde e doença na América Latina e Caribe. Rio de Janeiro: Editora Fiocruz; 2004. p. 393-425.

7. Chalhoub S. Cidade febril: cortiços e epidemias na Corte Imperial. São Paulo: Companhia das Letras; 1996.

8. Carvalho JM. Os bestializados: o Rio de Janeiro e a República que não foi. São Paulo: Companhia das Letras; 1987.

9. Meade T. "Civilizing Rio de Janeiro": the public health campaign and the riot of 1904. J Soc Hist 1986; 20(2):301-322.

10. Needell JD. The Revolta contra Vacina of 1904: the revolt against "modernization" in Belle Epoque Rio de Janeiro. Hisp Am Hist Rev 1987; 67(2):233-269.

11. Sevcenko N. A revolta da vacina: mentes insanas em corpos rebeldes. Nova ed. rev. São Paulo: Scipione; 1993.

12. Porter D, Porter R. The politics of prevention: antivaccinationism and public health in nineteenthcentury England. Med Hist 1988; 32(3):231-252.

13. Spier RE. Perception of risk of vaccine adverse events: a historical perspective. Vaccine 2001; 20(Suppl.1):S78-84; discussion S75-77.

14. Hochman G. A era do saneamento: as bases da politica de saúde pública no Brasil. São Paulo: Hucitec/ Anpocs; 1998

15. Hochman G. Regulando os efeitos da interdependência: sobre as relações entre Saúde Pública e Construção do Estado (Brasil 1910-1930). Estudos Históricos 1993; 6(11):40-61.

16. Tilly C. The formation of national states in Western Europe. Princeton, London: Princeton University Press; 1975.

17. Fernandes TMD. Vacina antivariólica: ciência, técnica e o poder dos homens, 1808-1920. $2^{\text {a }}$ ed. Rio de Janeiro: Editora Fiocruz; 2010.

18. Hochman G. Priority, invisibility and eradication: the history of smallpox and the Brazilian public health agenda. Med Hist 2009; 53(2):229-252.
19. Benchimol JL. Pereira Passos: um Haussmann tropical - a renovação urbana da cidade do Rio de Janeiro no início do século XX. Rio de Janeiro: Prefeitura da Cidade do Rio de Janeiro, Secretaria Municipal de Cultura, Turismo e Esportes, Departamento Gera de Documentação e Informação Cultural; 1990.

20. Benchimol JL. Manguinhos, do sonho à vida: a ciência na Belle Epoque. Rio de Janeiro: Casa de Oswaldo Cruz, Fiocruz; 1990.

21. Britto N. Oswaldo Cruz: a construção de um mito na ciência brasileira. Rio de Janeiro: Editora Fiocruz; 1995.

22. Stepan N. Beginnings of Brazilian science: Oswaldo Cruz, medical research and policy, 1890-1920. New York: Science History Publications; 1976.

23. Benchimol JL. Reforma urbana e Revolta da Vacina na cidade do Rio de Janeiro. In: Ferreira J, Delgado L, organizadores. O Brasil Republicano: o tempo do liberalismo excludente - da Proclamação da Republica à Revolução de 1930. Rio de Janeiro: Civilização Brasileira; 2003. p. 231-286.

24. Costa NR. Lutas urbanas e controle sanitário: origens das políticas de saúde no Brasil. Petrópolis, Rio de Janeiro: Vozes/Associação Brasileira de Pós-Graduação em Saúde Coletiva; 1985.

25. Pamplona MAV. Riots, republicanism, and citizenship: New York City and Rio de Janeiro City during the consolidation of the Republican order. New York: Garland Pub; 1996.

26. Scorzelli Jr. A. A importância da varíola no Brasil, 1964. Arquivos de Higiene 1965; 21:3-64.

27. Risi JB. Varíola. Arquivos de Higiene 1968; 24:119169.

28. Almáquio D. O Estado, o direito e a saúde pública. Rio de Janeiro: s/n.; 1929.

29. A Noite . Arquivo Carlos Chagas, Casa de Oswaldo Cruz, Fundação Oswaldo Cruz. 21/1/1926.

30. Hochman G, Fonseca CO. O que há de novo? Políticas de saúde pública e previdência, 1937-45. In: Pandolfi D, organizador. Repensando o Estado Novo. Rio de Janeiro: Editora FGV; 1999. p. 73-93.

31. Fonseca CMO. Saúde no Governo Vargas (19301945): dualidade institucional de um bem público. Rio de Janeiro: Editora Fiocruz; 2007.

32. Risi Júnior JB. A produção de vacinas é estratégica para o Brasil: entrevista com João Baptista Risi Júnior [entrevista]. Hist Cienc Saude - Manguinhos 2003;10(Supl.2):771-783.

33. Benchimol JL. Febre amarela: a doença e a vacina, uma história inacabada. Rio de Janeiro: Instituto de Tecnologia em Imunobiológicos, Editora Fiocruz; 2001.

34. Nascimento DR. Fundação Ataulpho de Paiva - Liga Brasileira contra a Tuberculose: um século de luta. Rio de Janeiro: Quadratim/Faperj; 2002.

35. Hochman G, Fonseca CMO. A I Conferência Nacional de Saúde: reformas, políticas e saúde pública em debate no Estado Novo. In: Gomes AC, organizador. Capanema: o ministro e seu ministério. Rio de Janeiro: Editora da FGV/EDUSF; 2000. p. 173-193.

36. Henderson DA. Smallpox: the death of a disease - the inside story of eradicating a worldwide killer. Amherst, N.Y.: Prometheus Books; 2009. 
37. Lee K. The World Health Organization (WHO). London, New York: Routledge; 2009.

38. Brasil. Oliveira, Juscelino Kubitschek de. Mensagem ao Congresso Nacional remetida pelo Presidente da República por ocasião da abertura da sessão legislativa de 1958. Rio de Janeiro: Imprensa Oficial; 1958.

39. Rodrigues BA. Smallpox eradication in the Americas. Bull Pan Am Health Organ 1975; 9(1):53-68.

40. Jarvis E. A contagious journey within a culture of complacency: the smallpox scare of 1962 in New York and Toronto. Can Bull Med Hist 2007; 24(2):343366.

41. Silva AM. Desenvolvimento e multilateralismo: um estudo sobre a Operação Pan-Americana no contexto da política externa de JK. Contexto Internacional 1992; 14(2):209-239.

42. Vizentini PF. A política externa do governo JK (195661). In: Albuquerque JAG, organizador. Sessenta anos de política externa brasileira, 1930-1990 - crescimento, modernização e política externa. São Paulo: USP, Núcleo de Pesquisas em Relações Internacionais; 1996.

43. Wilson LC, Dent WD Historical dictionary of InterAmerican organizations. Lanham, MD, London: The Scarecrow Press; 1998.

44. Taffet JF. Foreign aid as foreign policy: the Alliance for Progress in Latin America. New York: Routledge; 2007.

45. Información general - Reunión de Punta del Este, Uruguay. Boletin de la Oficina Sanitária Panamericana 1961; 40(5):473-493.

46. Hochman G. From autonomy to partial alignment: national malaria programs in the time of global eradication, Brazil, 1941-1961. Can Bull Med Hist 2008; 25(1):161-192.

47. Instituto Brasileiro de Geografia e Estatística (IBGE). Anuário estatístico do Brasil 1961, tabela IIIB3a (CD ROM Estatísticas do Século XX). Rio de Janeiro: Instituto Brasileiro de Geografia e Estatística; 2003.

48. Instituto Brasileiro de Geografia e Estatística (IBGE). Anuário Estatístico do Brasil 1964, tabela IIB3 (CDROM Estatísticas do Século XX). Rio de Janeiro: Instituto Brasileiro de Geografia e Estatística; 2003.

49. Pinheiro L. Politica externa brasileira (1889-2002). Rio de Janeiro: Jorge Zahar Editor; 2004.

50. Lima NT, Fonseca CMO, Hochman G. A saúde na construção do Estado Nacional no Brasil: a reforma sanitária em perspectiva histórica. In: Lima NT, Gerchman S, Edler FC, Suárez JM, organizadoresr. Saúde e democracia: história e perspectivas do SUS. Rio de Janeiro: Editora Fiocruz; 2005. p. 27-58.

51. Escorel S, Teixeira LA. História das políticas de saúde no Brasil de 1822 a 1963: do Império ao desenvolvimento populista. In: Giovanella L, Escorel S, Lobato L, Noronha JC, Carvalho AI, organizadores. Políticas e sistema de saúde no Brasil. Rio de Janeiro: Editora Fiocruz, Cebes; 2008. p. 333-384.

52. Labra ME. 1955-1964: o sanitarismo desenvolvimentista. In: Teixeira SF, organizador. Antecedentes da reforma sanitária. Rio de Janeiro: Escola Nacional de Saúde Pública Sergio Arouca; 1988. p. 9-36.

53. Jornal do Brasil 1962 Jan. 18; p. 3

54. O Correio da Manhã 1962 Jan. 24; p. 2.
55. Bastos NCB. SESP/FSESP: evolução histórica, 19421991. 2a ed. Brasília: Ministério da Saúde, Fundação Nacional de Saúde; 1996.

56. Plano de Operação para o Programa de Erradicação da Varíola no Brasil, c.1966. Caixa 20, fol. 20, Arquivo Cláudio do Amaral Jr, COC/Fiocruz, Rio de Janeiro, tabelas 1 e 2, p. 13-16.

57. Varíola - Trabalho para a Comissão Internacional de Certificação, 1973, caixa 51, fol. 3, p. 5-7, Arquivo Cláudio do Amaral Jr, COC/Fiocruz, Rio de Janeiro.

58. O Correio da Manhã 1966 Ago. 27; p. 11,

59. O Correio da Manhã 1966 Ago. 31; p. 7.

60. Folha de S. Paulo 1966 Ago. 27 ; p. 7

61. O Globo 1966 Ago.27; p. 3.

62. O Globo 1966 Ago. 30; p. 9.

63. O Estado de S. Paulo 1966 Ago. 31; p. 6.

64. O Globo 1966 Ago. 271966.

65. Varíola - Trabalho para a Comissão Internacional de Certificação, 1973, Quadro XXII, p. 44, Arquivo Cláudio do Amaral Jr., COC/Fiocruz, Rio de Janeiro.

66. O Globo 1966 Ago. 27 ; p. 3.

67. Correio da Manhã 1966 Ago. 27; p. 11.

68. Veronesi R, Gomes LF, Soares MA, Correa A. Importância de jet-injector (injeção sem agulha) em planos de imunização em massa no Brasil: resultados com as vacinas antitetânica e antivariólica. Rev Hosp Clin Fac Med Sao Paulo 1966; 21(2):92-95.

69. Millar JD, Morris L, Macedo Filho A, Mack TM, Dyal W, Medeiros AA. The introduction of jet injection mass vaccination into the national smallpox eradication program of Brazil. Trop Geogr Med 1971; 23(1):89-101.

70. Varíola - Trabalho para a Comissão Internacional de Certificação, 1973, caixa 51, fol.3, Arquivo Cláudio do Amaral Jr, COC/Fiocruz, Rio de Janeiro.

71. Manual do Vacinador, Box 50, fol. 15, Arquivo Cláudio do Amaral Jr., COC/Fiocruz, Rio de Janeiro. s/d.

72. Jornal do Brasil 1971 Abr. 30 ; p.13.

73. Palmer S, Hochman G. A Canada-Brazil network in the global eradication of smallpox. Can J Public Health 2010; 101(2):113-114,118.

74. Palmer S, Hochman G, Arbex D. Smallpox eradication, laboratory visits, and a touch of tourism: travel notes of a Canadian scientist in Brazil. Hist Cien Saude - Manguinhos 2010; 17:777-790.

75. Ponte CF. Vacinação, controle de qualidade e produção de vacinas no Brasil a partir de 1960. Hist Cien Saude - Manguinhos 2003;10(Supl.2):619-653.

76. Temporão JG. O Programa Nacional de Imunização no Brasil: origens e desenvolvimento. Hist Cien Saude - Manguinhos 2003; 10(Supl.2):601-617.

77. Plano de Operação para o Programa de Erradicação da Varíola no Brasil, c.1966, Caixa 20, fol. 20, p.11-12, Arquivo Cláudio do Amaral Jr, COC/Fiocruz, Rio de Janeiro.

78. Gazêta AAB, Cravalho DM, Tura LF, Gaze R. A Campanha de Erradicação da Varíola no Brasil e a Instituição do Sistema de Vigilância Epidemiológica. Cad Saude Colet 2005; 13(2):323-338.

79. Fenner F, Henderson DA, Arita I, Jezek Z, Ladnyi ID. Smallpox and its eradication. Geneva: World Health Organization; 1988. 